\title{
Prenatal Pesticide Exposure: Meconium as a Biomarker and Impact on Fetal Weight
}

Mona AH El-Baz ${ }^{1 *}$, Sahar EM El-Deek ${ }^{1}$, Ahmed Y Nsar ${ }^{1}$, Nagwa Abo El-Maali², Faten F AbdelHafez ${ }^{3}$ and Ahmed F Amin ${ }^{3}$

${ }^{1}$ Department of Medical Biochemistry, Assiut School of Medicine, Assiut University, Egypt

${ }^{2}$ Department of Analytical Chemistry, Faculty of Science, Assiut University, Egypt

${ }^{3}$ Women Health Hospital, Assiut School of Medicine, Assiut University, Egypt

\begin{abstract}
Background: Prenatal exposure to pesticides can adversely affect fetal health. This study aims to measure levels of some pesticides in meconium obtained from newborns whose mothers were exposed to pesticides, and to identify the effect of maternal exposure to pesticides on neonatal weight.

Methods: This is a cross-sectional study. It was carried out on 190 cases (106 exposed and 84 non-exposed to pesticides). Nine pesticides (pretilachlor, DDT, lindane, chloropyrifos, diazinon, malathion, bioallethrin, a cyprmethrin and $\beta$ cyfluthrin) were detected by Gas Chromatography/ Mass Spectrometry (GC/MS).

Results: The frequencies of pesticides detection in the samples were: $54.7 \%, 57.4 \%, 50 \%, 35.8 \%, 53.7 \%, 49.5 \%$, $34.7 \%, 41.1 \%$ and $21.5 \%$ respectively. Those who reported prenatal exposure to pesticides were four times more likely to work in agricultural work $(\mathrm{OR}=4.5,95 \% \mathrm{Cl}=2.1-9.8)$. Moreover, those who reported prenatal exposure to pesticides were 1.6 times more likely to have babies with low birth weight $(\mathrm{OR}=1.59,95 \% \mathrm{Cl}=1.2-6.3)$.
\end{abstract}

Conclusions: Agricultural pregnant workers in our community were significantly more exposed to several types of pesticides and this was associated with impaired fetal growth.

Keywords: Prenatal pesticides; Meconium; Gas Chromatography/ Mass Spectrometry (GC/MS); IUGR

\section{Introduction}

Intrauterine growth restriction (IUGR) is a common complication of pregnancy, affecting nearly $5-10 \%$ of newborns and is associated with increased infant mortality as well as childhood morbidity. Although the etiology of IUGR may be a consequence of several factors (such as metabolic factors, maternal infection, under nutrition, drug abuse and placental disorders), in $40 \%$ of cases, the cause is idiopathic. Environmental pollutants, oxidative stress and interaction between pollutant, free radicals and cellular system play an important role in reproductive toxicology and development of IUGR [1].

Developmental diseases such as birth defects, IUGR, and preterm delivery, account for more than $25 \%$ of infant mortality and morbidity [2]. Common risk factors such as smoking, alcohol use, older maternal age, and low socioeconomic status cause adverse fetal development [3]. Recently, it has been suggested that environmental risk factors and maternal occupation may also play an important role [4].

Pesticides are a group of environmental pollutants that pose a major risk to human health. These toxic pollutants are chemically stable and may persist as contaminants in the environment [5].

The exposure of pregnant women to pesticides is a major public health concern because these pesticides are neurotoxic to the fetus $[6,7]$. Moreover, some epidemiologic studies have shown that parental exposure to pesticides is a risk factor for childhood leukemia [8].The exact cause is still unknown but chromosomal abnormalities and DNA damages are thought to be the underlying mechanisms [9].

Exposure of a pregnant woman to pesticides derives from environmental, occupational as well as domestic exposures. These pesticides may reach the fetus during gestation and after birth via breast-feeding. The detection of these pesticides has been demonstrated in maternal, umbilical cord, placental and new-born blood samples $[10,11]$. However pesticides in these matrices are bio- markers of shortterm or recent exposure and do not show past or cumulative exposure [5].
Meconium is an ideal matrix for measuring prenatal exposure to pesticides. It is formed early in gestation and most xenobiotics and pesticides are deposited in it. Since meconium is not normally excreted in utero, pesticides deposited in meconium accumulate and increase in concentration which enhances the chance of their detection [7]. In addition, its collection is easy and non-invasive [12].

Detection of pesticides in biological samples from exposed persons is in rapid development. Recent research is focusing more on those pesticides that are considered to be endocrine-disrupting and potential risk factors for the development of leukemia and lymphoma [13]. More specifically, researches have focused on organophosphates, organochlorine pesticides, synthetic pyrethroid insecticides, triazines, chlorophenols and neurotoxic carbamates. All these compounds are of scientific interest because of their widespread use and their potential toxicology risk for human health [13].

\section{Aims of the Study}

1-To measure the levels of pesticides in meconium obtained from infants whose mothers were exposed to pesticides. 2- To identify the risk of maternal exposure to pesticides on the birth weight of the newborns.

*Corresponding author: Mona AH El-Baz, Department of Medical Biochemistry, Assiut School of Medicine, Assiut University, 71515, Egypt, Tel: +201005800409; E-mail: monaelbaz1@gmail.com

Received December 08, 2014; Accepted January 15, 2015; Published January 20, 2015

Citation: El-Baz MAH, El-Deek SEM, Nsar AY, El-Maali EA, AbdelHafez FF, Amin AF (2015) Prenatal Pesticide Exposure: Meconium as a Biomarker and Impact on Fetal Weight. J Environ Anal Toxicol 5: 268. doi:10.4172/2161-0525.1000268

Copyright: (c) $2015 \mathrm{El-Baz} \mathrm{MAH,} \mathrm{et} \mathrm{al.} \mathrm{This} \mathrm{is} \mathrm{an} \mathrm{open-access} \mathrm{article} \mathrm{distributed}$ under the terms of the Creative Commons Attribution License, which permits unrestricted use, distribution, and reproduction in any medium, provided the original author and source are credited. 


\section{Subjects and Methods}

\section{Subjects}

This cross sectional study was carried out on 190 delivering women from the labor ward of Women Health Hospital, Assiut University, Egypt between 2010 and 2012. These women were classified into 2 groups; 106 exposed and 84 non-exposed to pesticides. A questionnaire survey of the participants was conducted to collect general demographic information such as the type of pesticides used at home or in the farm, socioeconomic status, and source of water supply, dietary habits, educational level, maternal occupational characteristic, lifestyle habits, and maternal health.

Information about newborns was registered including gestational age, birth weight, and Apgar score. Apgar score is a score that quickly assesses the health of newborn. Scores of 7 and above were normal, 4 to 6 fairly low, and 3 and below were critically low [14].

After birth, meconium was collected from the newborns' diapers and pooled into sterile polypropylene containers. Meconium samples were frozen at $-20^{\circ} \mathrm{C}$ until the time of analysis of pesticides.

Mothers with serious chronic diseases such as diabetes, hypertension, anemia, renal diseases, heart diseases, thyroid disease or those who developed a serious pregnancy complication that could affect the fetal growth and development were excluded from the study. Cases with symmetrical IUGR, history of passive smoking and chronic drug intake were also excluded from the study.

An informed consent was obtained from each woman for her and her newborn's participation in the study. The study was approved by the Local Ethics Committee of Faculty of Medicine, Assiut University.

\section{Meconium extraction}

This extraction took place according to the method described by Ostrea [15]. Meconium (0.5 g) was weighed. Five mls methanol: phosphate buffer was added, and then sonicated for about $10 \mathrm{~min}$ until it became homogeneous. The samples were then centrifuged at $4000 \mathrm{rpm}$ for $30 \mathrm{~min}$. Subsequently, $1.2 \mathrm{ml}$ hexane was added, and the mixture was centrifuged again for $2 \mathrm{~min}$. The mixture was settled and the organic layer was separated in vials until injected to GC/MS. Positive controls and calibrators were spiked with $100 \mu \mathrm{l}$ of the appropriate concentration of pesticide mixture at this time and vortexed. Finally the mixture was centrifuged for $30 \mathrm{~min}$ at $4000 \mathrm{rpm}$ and the supernatant was saved for further analysis.

\section{Chemical preparation}

Pesticide Mix in hexane was composed of: pretilachlor, DDT, lindane, chlorpyrifos, diazinon, Malathion, bioallethrin, $\beta$ cyfluthrrin and a cypermethrin. Pesticide Mix was custom synthesized and purchased from Sigma with cat. No. (SZE9015X, SZE9315X, SZE7038X, SZE8071X, 45428, 36143, SZE8287X, SZE7144X, and SZE5024X for the above pesticides, respectively).

\section{Gas Chromatography-Mass Spectrometry instrumentation (GC/MS)}

GC separation was performed using Gas Chromatograph from Agilent Technologies Model 7890A equipped with temperature programming capability, splitless injector, and capillary column with helium as the carrier gas at $36.796 \mathrm{~cm} / \mathrm{sec}$ with a flow-rate of $1 \mathrm{ml} \mathrm{min}$ ${ }^{1}$. The injection port temperature was $250^{\circ} \mathrm{C}$ and interface temperature was $280{ }^{\circ} \mathrm{C}$. The DB-5ms column was used for chromatographic separation of analytes. The splitless injector $\left(250^{\circ} \mathrm{C}\right)$ was used for injection of about $1 \mu \mathrm{l}$ of injection volume. Detection was performed by Mass Quadruple Spectrometry detector Model 5975B. A computer data system (MSD ChemStation E.0201.1177) was used for measuring peak areas and heights.

Method validation, Quality control, analysis of laboratory reagent blanks (LRB), initial demonstration of capability, analysis of laboratory fortified blanks (LFB) were performed according to the methods described by Bielawski [12].

\section{Calibration standards and quality control materials}

Solid phase extraction was done according to the method described by Keith [16] using a solid phase extraction filter. Spiked-matrix calibration curves were constructed for the quantitation of pesticide and metabolite compounds. From the linear curve, the unknown and control sample concentrations were determined.

\section{Statistical analysis}

Data were collected, verified then analyzed using SPSS statistical package (version 16). The results were presented as mean $\pm S D$, number and percentages. To determine the significance of non-parametric categorical variables, Chi-square test was calculated. Mann-Whitney U test analysis was carried out for non-parametric continuous variables. Multivariate logistic regression models were built to detect the most important predictors for pesticides exposure among the study sample and this was conducted using STATA (version 12.0) software. Adjusted odds ratio (AOR), Likelihood ratio test (LHR) and 95\% confidence intervals (95\% CIs) were calculated to assess significance in the models. Collinearity was investigated for the predictors involved in the analysis. Spearman's rank correlations were carried out to explore any possible collinearity among predictors. To test for the validity of these results, collinearity diagnostic tests (Tolerance and Variance Inflation Factor 'VIF') were conducted. Multi-collinearity was assumed if the tolerance below 0.5 and/or VIF above 10. A significant P-value was considered when $<0.05$.

\section{Results}

\section{Demographic characteristics}

The socio-demographic data of study groups were described in (Table 1). The study included 190 subjects. There were 145 subjects who lived in rural areas and 45 who lived in urban areas. Agricultural workers were significantly associated with pesticide exposure $(\mathrm{P}<0.001)$. Baseline characteristics related to pregnancy and labor of the studied samples were described in (Table 2). Birth outcomes in the form of birth weight and Apgar score were shown. Low birth weight was present in $65.4 \%$ of exposed group versus $34.6 \%$ of the nonexposed group $(\mathrm{P}<0.01)$.

\section{Concentration of pesticides in postpartum meconium}

The levels of pesticides in postpartum meconium samples were described in (Table 3). We studied four classes of pesticides including chloroacetanilide (as pretilachlor), organochlorine (as DDT and lindane), organophosphate (as chlorpyrifos, diazinon and Malathion) and pyrethroid (as bioallethrin, $\beta$ cyfluthrrin and $\alpha$ cypermethrin). So nine types of pesticides were detected in the samples with significant rise in their levels.

As regards to the comparison of the pesticides levels in postpartum meconium in exposed and non-exposed groups, there was significant increase in the levels of DDT, lindane, diazinone, malathion, 
Citation: El-Baz MAH, El-Deek SEM, Nsar AY, El-Maali EA, Abdel Hafez FF, Amin AF (2015) Prenatal Pesticide Exposure: Meconium as a Biomarker and Impact on Fetal Weight. J Environ Anal Toxicol 5: 268. doi:10.4172/2161-0525.1000268

Page 3 of 6

\begin{tabular}{|c|c|c|c|}
\hline Parameters & $\begin{array}{c}\text { Exposed group } \\
(n=106)\end{array}$ & $\begin{array}{l}\text { Non-exposed } \\
\text { group }(n=84)\end{array}$ & P-value \\
\hline Maternal Age in years ${ }^{+}$ & $27.2 \pm 6.3$ & $26.5 \pm 6.5$ & NS \\
\hline \multicolumn{3}{|l|}{ Residence } & \multirow{3}{*}{ NS } \\
\hline Rural & $80(55.2 \%)$ & $65(44.8 \%)$ & \\
\hline Urban & $26(57.8 \%)$ & $19(42.2 \%)$ & \\
\hline \multicolumn{3}{|l|}{ Educational state: } & \multirow{3}{*}{ NS } \\
\hline Educated & $29(56.9 \%)$ & $22(43.1 \%)$ & \\
\hline Non educated & 77 (55.4\%) & $62(44.6 \%)$ & \\
\hline \multicolumn{3}{|l|}{ Type of Work } & \multirow{3}{*}{$<0.001^{*}$} \\
\hline Agricultural & $94(63.1 \%)$ & $55(36.9 \%)$ & \\
\hline Non-agricultural & $12(29.3 \%)$ & $29(70.7 \%)$ & \\
\hline
\end{tabular}

+ Mean \pm SD

*Highly significant

Table 1: Socio-demographic characteristics of the studied pregnant women (Exposed vs. Non-exposed)

\begin{tabular}{|c|c|c|c|}
\hline Parameters & $\begin{array}{l}\text { Exposed group } \\
(n=106)\end{array}$ & $\begin{array}{c}\text { Non-exposed group } \\
(n=84)\end{array}$ & P-value \\
\hline Numbers of abortions ${ }^{+}$ & $0.57 \pm 1.0$ & $0.46 \pm 0.7$ & NS \\
\hline Gestational age in weeks ${ }^{+}$ & $37.37 \pm 2.1$ & $37.43 \pm 2.3$ & NS \\
\hline Hospital Stay in days ${ }^{+}$ & $1.9 \pm 1.3$ & $1.7 \pm 0.8$ & NS \\
\hline \multicolumn{3}{|l|}{ Numbers of Deliveries } & \multirow{3}{*}{ NS } \\
\hline Primipara & $34(57.6 \%)$ & $25(42.4 \%)$ & \\
\hline Multipara & $65(54.6 \%)$ & $54(45.4 \%)$ & \\
\hline \multicolumn{3}{|l|}{ Type of Delivery } & \multirow{3}{*}{ NS } \\
\hline Vaginal delivery & $40(51.9 \%)$ & $37(48.1 \%)$ & \\
\hline Cesarean section & $66(58.4 \%)$ & $47(41.6 \%)$ & \\
\hline \multicolumn{4}{|l|}{ Birth Outcome } \\
\hline Birth Weight in $\mathbf{K g}^{+}$ & 3. $09 \pm 0.5$ & 3. $10 \pm 0.7$ & NS \\
\hline APGAR Score ${ }^{+}$ & $9.49 \pm 1.01$ & $9.61 \pm 1.11$ & NS \\
\hline \multicolumn{3}{|l|}{ Low Birth Weight } & \multirow[b]{3}{*}{$<0.01^{*}$} \\
\hline Present & $17(65.4 \%)$ & $9(34.6 \%)$ & \\
\hline Absent & $89(54.3 \%)$ & $75(45.7 \%)$ & \\
\hline
\end{tabular}

+ Mean \pm SD

*Significant

Table 2: Baseline characteristics related to pregnancy and labour of the studied samples (Exposed vs. Non-exposed)

\begin{tabular}{|c|c|c|c|}
\hline Pesticides & $\begin{array}{c}\text { Exposed group } \\
(\mathbf{n = 1 0 6})\end{array}$ & $\begin{array}{c}\text { Non-exposed group } \\
(\mathbf{n = 8 4})\end{array}$ & P-value* $^{*}$ \\
\hline $\begin{array}{c}\text { Chloroacetanilide } \\
\text { Pretilachlor }\end{array}$ & $74.3 \pm 506.1$ & $38.8 \pm 149.5$ & NS \\
\hline Organochlorine & & & \\
\hline DDT & $510.4 \pm 3411.8$ & $37.43 \pm 59.9$ & $<\mathbf{0 . 0 1}$ \\
\hline Lindane & $76.2 \pm 138.8$ & $13.7 \pm 180.2$ & $<\mathbf{0 . 0 0 1}$ \\
\hline Organophosphate & & & NS \\
\hline Chlorpyrifos & $81.6 \pm 279.1$ & $74.4 \pm 216.0$ & $<\mathbf{0 0 1}$ \\
\hline Diazinon & $287.4 \pm 952.8$ & $29.9 \pm 81.2$ & $<\mathbf{0 0 1}$ \\
\hline Malathion & $389.9 \pm 773.7$ & $86.1 \pm 247.6$ & \\
\hline Pyrethroid & & & $<\mathbf{0 1}$ \\
\hline Bioallethrin & $35.4 \pm 5392.9$ & $22.0 \pm 5524.6$ & $<0.05$ \\
\hline $\boldsymbol{\beta}$ - Cyfluthrin & $768.3 \pm 952.8$ & $135.7 \pm 81.2$ & NS \\
\hline $\boldsymbol{\alpha}$ - Cypermethrin & $285.7 \pm 893.6$ & $170.5 \pm 539.7$ & \\
\hline
\end{tabular}

+ Mean \pm SD

*Mann-Whitney non-parametric test was used to compare the mean difference between the two groups

Table 3: Comparison between pesticides levels $(\mu \mathrm{g} / \mathrm{g})$ in meconium among exposed vs. non-exposed groups

bioallethrin and $\beta$-cyfluthrin in the exposed versus non-exposed group (Table 3). Comparing the pesticides levels in subjects living in rural and urban area, there was significant increase in the levels of lindane and Malathion in rural versus urban areas $(\mathrm{P}<0.05$ and $\mathrm{P}<0.001$ respectively) as shown in (Table 4).

\section{Concentration of pesticides and birth weight}

The comparison of pesticides levels in meconium of low and normal birth weight groups were shown in (Table 5). There was a significant increase in the mean meconium levels of pretilachlor, DDt, lindane, chlorpyrifos, diazinon, malathion and bioallethrin in the low versus normal birth weight group.

\section{Logistic regression model for exposure to pesticides among the studied groups}

The final logistic regression model for exposure to pesticides among studied group was described in (Table 6). This model included work and birth weight. Those who reported prenatal exposure to pesticides were four times more likely to work in agricultural work $(\mathrm{OR}=4.5$, $95 \% \mathrm{CI}=2.1-9.8)$. Similarly, those who reported prenatal exposure to pesticides were 1.6 times more likely to have babies with low birth weight $(\mathrm{OR}=1.59,95 \% \mathrm{CI}=1.2-6.3)$.

\section{Discussion}

Detection of fetal exposure to environmental pesticides is so important. Many of the pesticides are neurotoxic and fetal exposure to these compounds could adversely affect prenatal and subsequent neurodevelopment. Adverse birth outcome, poor motor and cognitive development, and leukemia in childhood were reported [8,17-19]. The aim of our study was to determine fetal exposure to environmental pesticides in our community by measuring its levels in the meconium, to identify infants who are at risk at birth, and to identify whether exposure to pesticides might adversely influence the weight of the fetus.

The high rate of detection of pesticides in meconium is attributed to the repository nature of it, thus providing a wide window of exposure to xenobiotics. Meconium is formed at around the third or fourth month of gestation and most xenobitics that the fetus is exposed to during gestation are deposited in meconium, through fetal swallowing or bile secretion from that period up to the time of birth. Compounds that deposit in meconium accumulate and increase in concentration, thus enhancing their detection $[7,20]$. On the other hand, pesticides in cord blood represent acute exposure and may not be readily detected due to low concentration as a result of the metabolism, excretion and deposition in tissues $[7,20]$. Each matrix provides specific information on pesticides exposure. Meconium and hair can indicate cumulative exposure, while amniotic fluid is an indicator of acute fetal exposure to xenobiotics [21].

The results of the present study showed that there was a significant rise in the levels of pesticides including pretilachlor, DDT, lindane, chloropyrifos, diazinon, malathion, bioallethrin, $\alpha$ cyprmethrin and $\beta$ cyfluthrin in postpartum meconium samples that were collected from newborns of mother exposed to pesticides in the agricultural area or at home. These results were in agreement with that of Wyatt and Barr, 2001 who showed that, organophosphate metabolites, diazinon and chlorpyrifos could be detected in postpartum meconium in about 95 $\%$ of the examined sample. These pesticides were of concern due to the fact that prenatal exposure has been linked experimentally to adverse neurodevelopmental sequel in the offspring. They added that, the level of these pesticides were higher than those detected in umbilical 


\begin{tabular}{|c|c|c|c|}
\hline Pesticides $^{+}$ & $\begin{array}{l}\text { Rural group } \\
(n=145)\end{array}$ & $\begin{array}{l}\text { Urban group } \\
\quad(n=45)\end{array}$ & P-value* \\
\hline $\begin{array}{l}\text { Chloroacetanilide } \\
\text { Pretilachlor }\end{array}$ & $63.3 \pm 402.1$ & $26.2 \pm 86.4$ & NS \\
\hline \multicolumn{4}{|l|}{ Organochlorine } \\
\hline DDT & $731.6 \pm 4667.1$ & $78.7 \pm 186.7$ & NS \\
\hline Lindane & $101.7 \pm 285.2$ & $36.8 \pm 97.9$ & $<0.05$ \\
\hline \multicolumn{4}{|l|}{ Organophosphate } \\
\hline Chlorpyrifos & $118.8 \pm 276.1$ & $64.8 \pm 234.4$ & NS \\
\hline Diazinon & $290.8 \pm 1239.3$ & $98.0 \pm 267.2$ & NS \\
\hline Malathion & $419.8 \pm 662.0$ & $158.5 \pm 519.3$ & $<0.001$ \\
\hline \multicolumn{4}{|l|}{ Pyrethroid } \\
\hline Bioallethrin & $30.9 \pm 172.5$ & $18.3 \pm 70.62$ & NS \\
\hline$\beta$-Cyfluthrin & $125.8 \pm 4863.4$ & $104.7 \pm 5567.3$ & NS \\
\hline$\alpha-$ Cypermethrin & $315.4 \pm 691.1$ & $209.7 \pm 778.3$ & NS \\
\hline
\end{tabular}

\section{+ Mean \pm SD}

*Mann-Whitney non-parametric test was used to compare the mean difference between the two groups

Table 4: Comparison of pesticides levels $(\mu \mathrm{g} / \mathrm{g})$ in meconium of rural and urban groups

\begin{tabular}{|c|c|c|c|}
\hline Pesticides $^{+}$ & $\begin{array}{c}\text { Low Birth Weight } \\
\text { (no=26) }\end{array}$ & $\begin{array}{c}\text { Normal Weight } \\
\text { (no=164) }\end{array}$ & P-value* $^{*}$ \\
\hline $\begin{array}{c}\text { Chloroacetanilide } \\
\text { Pretilachlor }\end{array}$ & $162.8 \pm 812.6$ & $32.6 \pm 132.0$ & $<\mathbf{0 . 0 1}$ \\
\hline Organochlorine & $119.4 \pm 5510.8$ & $38.6 \pm 83.3$ & $<\mathbf{0 . 0 0 1}$ \\
\hline DDT & $256.5 \pm 333.0$ & $10.8 \pm 17.9$ & $<\mathbf{0 . 0 0 1}$ \\
\hline Lindane & $237.1 \pm 470.6$ & $45.2 \pm 149.7$ & $<\mathbf{0 . 0 1}$ \\
\hline Organophosphate & $773.9 \pm 1432.1$ & $16.0 \pm 41.8$ & $<\mathbf{0 . 0 0 1}$ \\
\hline Chlorpyrifos & $100.3 \pm 968.0$ & $61.8 \pm 223.4$ & $<\mathbf{0 . 0 0 1}$ \\
\hline Diazinon & $104.5 \pm 293.6$ & $12.4 \pm 101.3$ & $<\mathbf{0 . 0 0 1}$ \\
\hline Malathion & $684.7 \pm 799.7$ & $313.2 \pm 990.0$ & $\mathrm{NS}$ \\
\hline Pyrethroid & $450.9 \pm 995.8$ & $190.9 \pm 696.2$ & $\mathrm{NS}$ \\
\hline Bioallethrin & $\boldsymbol{\beta}$ - Cyfluthrin & & \\
\hline $\boldsymbol{\alpha}$ - Cypermethrin & & & \\
\hline
\end{tabular}

\section{+ Mean \pm SD}

*Mann-Whitney non-parametric test was used to compare the mean difference between the two groups

Table 5: Comparison of pesticides levels $(\mu \mathrm{g} / \mathrm{g})$ in meconium of low birth weight and normal birth weight groups

cord blood and appear stable in meconium over 12 hours at room temperature [22].

In the present study the frequencies of pesticides detection in the samples were: $54.7 \%, 57.4 \%, 50 \%, 35.8 \%, 53.7 \%, 49.5 \%, 34.7 \%$, $41.1 \%$ and $21.5 \%$ to pretilachlor, DDT, lindane,chloropyrifos, diazinon, malathion, bioallethrin, $\alpha$ cyprmethrin and $\beta$ cyfluthrin, respectively. These frequencies were higher than those reported by other investigators. Ostrea found that, the highest rates of pesticide exposure were detected in meconium of newborns of pregnant women in agricultural site $(2.0 \%$ to pretilachlor, $1.7 \%$ to cypermethrin, $0.8 \%$ to cyfluthrin, $0.7 \%$ to DDT and $0.3 \%$ to malathion and bioallethrin) $[7,20]$. In addition, they reported that, there was significant exposure of the pregnant woman and her fetus to pesticides, particularly to home pesticides, propoxure and pyrethroids [7,20]. Analysis of meconium was the single most sensitive measure of exposure. The accumulation of pesticides in meconium, the ease of collection and its large amount that could be collected were factors that increased the sensitivity of this matrix. Of the eleven pesticides analyzed, eight were detected including

propoxur, malathion, bioallethrin, pretilachlor, DDT, cyfluthrin, cypermethrin and chlorpyrifos. Furthermore, the concentrations were significantly higher in meconium than in cord blood and infant hair. However, combined analysis of maternal hair and meconium significantly increased the detection rate and could help to minimize further exposure to the pesticides $[7,20]$.

Moreover, Woodruff demonstrated that certain polychlorinated biphenyls, organochlorine pesticides, phenols, phathalates, polycyclic aromatic hydrocarbons and perchlorates were detected in $99-100 \%$ of USA examined pregnant women. This indicated that pregnant women were exposed to multiple chemicals and further efforts were needed to understand sources of exposure [23].

In addition, many researchers showed that DDT, present in food and fish, accumulates in fat tissue, biomagnifies through the food chain and is detected in blood of general population. Consequently it interferes with fetal growth through interaction with endogenous steroid hormone signaling [24-28].

The results of the present study showed that, pesticides could be detected in meconium samples of newborns of mothers living in both urban and rural areas but there was significant increase in meconium levels of organochlorines (DDT, lindane) and organophosphates (diazinone and malathion) in rural area. Tsatsakis who performed a study on pregnant woman in rural areas in Crete, Greece, found that there was a significant increase in the levels of organophosphate in meconium of newborns of the pregnant women in rural areas. These results demonstrated that organophosphate in meconium may be considered as a potential biomarker for the assessment of prenatal fetal exposure [29].

Ostrea reported that exposure to home, rather than farm, pesticides was the major source of pesticides exposure in the pregnant woman and her fetus even in an agricultural environment [20]. Similarly, other studies showed that, whether in the urban or rural area, home pesticides constituted a high health risk in pregnant woman and were likely related to its widespread and inappropriate use [15,30,31]. Poor education and inadequate labeling on the safe use of the pesticide were major reasons for its improper use [20]. Prenatal pesticide exposure in the mother could be detected and intervention measures could be initiated to minimize further exposure of the fetus to pesticides [20].

Low birth weight was more common in cases exposed to pesticides. Pesticides detected in significantly high concentrations included; chloroacetanilide (pretilachlor), organochlorines (DDT and lindane), organophosphates (chlorpyriphos, diazinon and malathion) and pyrethroid (bioallethrin). These results were in agreement with others who reported that, IUGR was associated with organochlorine pesticide residue levels $[1,19,32)$. The underlying mechanism is unclear but mostly through endocrine disrupters [19]. The current study showed that women who reported prenatal exposure to pesticides were 1.6 times more likely to have babies with low birth weight. This in agreement with the results reported by Govarts who stated that, low level exposure of polychlorinated biphenyls impaired fetal growth and birth weight [33]. Similarly, Nieuwenhuijsen showed significant associations between environmental exposure to pesticides, chemicals, air pollution, tobacco smoke and pregnancy outcome in the form of stillbirth, decreased birth weight and congenital anomalies [34]. On the contrary, Dordevic reported that, there was no difference in birth weight, length and head circumference between exposed and non-exposed newborn [9]. However, Dordevic and Ostrea reported that CNS disorders were present more in the pesticides exposed than in pesticides non-exposed newborns $[9,18]$ 
Citation: El-Baz MAH, El-Deek SEM, Nsar AY, El-Maali EA, Abdel Hafez FF, Amin AF (2015) Prenatal Pesticide Exposure: Meconium as a Biomarker and Impact on Fetal Weight. J Environ Anal Toxicol 5: 268. doi:10.4172/2161-0525.1000268

Page 5 of 6

\begin{tabular}{|c|c|c|c|}
\hline & AOR $^{* *}$ & $\mathbf{9 5 \%} \mathbf{C l}^{* *}$ & LRT $^{+} \mathbf{P}$-value \\
\hline Type of Work & & & \multirow{2}{*}{$<0.001$} \\
\hline Non-agricultural & 1 & & \\
\hline Agricultural & 4.53 & $2.1-9.8$ & \multirow{2}{*}{$<0.05$} \\
\hline Low Birth Weight & & & \\
\hline Absent & 1 & $1.2-6.3$ & \\
\hline Present & 1.59 & \\
\hline
\end{tabular}

*Initial model included maternal age, work status, number of deliveries, number of abortions, residence, pregnancy duration and birth weight categories

${ }^{*}$ Final model included work and birth weight only

**Adjusted Odds Ratio, $\mathrm{Cl}=$ Confidence Interval

+LRT=Likelihood Ratio Test

Table 6: Final ${ }^{*}$ Logistic Regression Model for exposure to pesticides among the studied groups

The effect of perinatal exposure to pesticides was also studied in animals [35-37]. Gomes and Lloyd studied the effect of organophosphorous pesticide on gestational outcomes in mice. They found that fetal weights were significantly lower in the exposed group compared to controls [35]. Likewise, Ahmed found that, intrauterine exposure to chloroacetonitrle decreased fetal body weight and induced malformations in the musculoskeletal system in mice [36].

In addition, Saillenfait reported that, oral administration of di-nhexyl phthalate to rats caused developmental toxic effects, including marked embryo mortality and presence of malformation and significant decrease in fetal weight [37].

Women in pesticides exposed areas who intend to become pregnant as well as pregnant women are at high risk for adverse outcomes, thus it is important to identify occupational-related risk factors for prevention. Occupations in which women have a high exposure probability are agricultural industry and occupations involving the use of home pesticides. Since the effect of occupational exposure on fetal growth is considerable, pregnant women should be informed about the potential risk of pesticides exposure in workplace on birth weight. Further studies are needed to identify the molecular basis of the effects, to study the epigenetic effects of these exposures and to develop strategies to prevent exposure to these agents to improve birth outcome $[19,33]$.

\section{Conclusions}

The results of the present study showed that pregnant women in our community including both rural and urban areas are significantly exposed to several types of pesticides particularly home and farm pesticides. Maternal occupational exposure is associated with impaired fetal growth but further studies are needed to confirm these findings, to evaluate the dose-response relationship and to assess post-natal complications that may occur later on.

\section{Highlights}

Pregnant women with prenatal exposure to pesticides were four times more likely to work in agricultural work

Similarly, those who reported prenatal exposure to pesticides were 1.6 times more likely to have babies with low birth weight

Occupations in which women have a high pesticide exposure probability are agricultural industry and occupations involving the use of home pesticides.

Since the effect of occupational exposure on fetal growth is considerable, pregnant women should be informed about the potential risk of pesticides exposure in workplace on birth weight.

\section{Acknowledgments}

Authors are grateful to Quality Assurance Unit of Faculty of Medicine, Assiut University, Egypt for its financial support.

\section{References}

1. Pathak R, Mustafa MD, Ahmed T, Ahmed RS, Tripathi AK, et al. (2011) Intra uterine growth retardation: Association with organochlorine pesticide residue levels and oxidative stress markers. Reprod Toxicol 31: 534-539.

2. Liu X, Roth J (2008) Development and validation of an infant morbidity index using latent variable models. Stat Med 27: 971-989.

3. Silva LM, Jansen PW, Steegers EA, Jaddoe VW, Arends LR, et al. (2010) Mother's educational level and fetal growth: the genesis of health inequalities. Int J Epidemiol 39: 1250-1261.

4. Li X, Sundquist J, Sundquist K (2010) Parental occupation and risk of smallfor-gestational-age births: a nationwide epidemiological study in Sweden. Hum Reprod 25: 1044-1050.

5. Posecion N Jr, Ostrea E Jr, Bielawski D, Corrion M, Seagraves J, et al. (2006) Detection of Exposure to Environmental Pesticides During Pregnancy by the Analysis of Maternal Hair Using GC-MS. Chromatographia 64: 681-687.

6. Barone S Jr, Das KP, Lassiter TL, White LD (2000) Vulnerable processes of nervous system development: a review of markers and methods. Neurotoxicology 21: 15-36

7. Ostrea EM Jr, Bielawski DM, Posecion NC Jr, Corrion M, Villanueva-Uy E, et al (2008) A comparison of infant hair, cord blood and meconium analysis to detect fetal exposure to environmental pesticides. Environ Res 106:277-83.

8. Ward MH, Colt JS, Metayer C, Gunier RB, Lubin J, et al. (2009) Residentia exposure to polychlorinated biphenyls and organochlorine pesticides and risk of childhood leukemia. Environ Health Perspect 117: 1007-1013.

9. Dordevic M, Vujic A, Jovanovic B, Dordevic G, Sazdanovic M, et al. (2010) Neonatal outcome following exposure to organophosphorous pesticides. Arch Biol Sci Belgrade 62: 1-8.

10. Doucet J, Tague B, Arnold DL, Cooke GM, Hayward S, et al. (2009) Persistent organic pollutant residues in human fetal liver and placenta from Greater Montreal, Quebec: a longitudinal study from 1998 through 2006. Environ Health Perspect 117: 605-610.

11. Sereda B, Bouwman H, Kylin H (2009) Comparing water, bovine milk, and indoor residual spraying as possible sources of DDT and pyrethroid residues in breast milk. J Toxicol Environ Health A 72: 842-851.

2. Bielawski D, Ostrea E Jr, Posecion N Jr, Corrion M, Seagraves J (2005) Detection of several classes of pesticides and metabolites in meconium by gas chromatography-mass spectrometry. Chromatographia 62:623-629.

13. Margariti MG, Tsakalof AK, Tsatsakis AM (2007) Analytical methods of biological monitoring for exposure to pesticides: recent update. Ther Drug Monit 29: 150-163.

14. APGAR V (1953) A proposal for a new method of evaluation of the newborn infant. Curr Res Anesth Analg 32: 260-267.

15. Ostrea EM, Morales V, Ngoumgna E, Prescilla R, Tan E, et al. (2002) Prevalence of fetal exposure to environmental toxins as determined by meconium analysis. Neurotoxicology 23: 329-339.

16. Keith LH (1996) Compilation of epa's sampling and analysis methods 2nd ed Boca Raton, FL : Lewis Publishers: CRC Press.

17. Engel SM, Wetmur J, Chen J, Zhu C, Barr DB, et al. (2011) Prenatal exposure to organophosphates, paraoxonase 1, and cognitive development in childhood. Environ Health Perspect 119: 1182-1188.

18. Ostrea EM Jr, Reyes A, Villanueva-Uy E, Pacifico R, Benitez B, et al. (2012 Fetal exposure to propoxur and abnormal child neurodevelopment at 2 years of age. Neurotoxicology 33: 669-675.

19. Snijder CA, Roeleveld N, Te Velde E, Steegers EA, Raat H, et al. (2012) Occupational exposure to chemicals and fetal growth: the Generation R Study. Hum Reprod 27: 910-920.

20. Ostrea EM Jr, Bielawski DM, Posecion NC Jr, Corrion M, Villanueva-Uy E, et al. (2009) Combined analysis of prenatal (maternal hair and blood) and neonatal (infant hair, cord blood and meconium) matrices to detect fetal exposure to environmental pesticides. Environ res. 109:116-122. 
Citation: El-Baz MAH, El-Deek SEM, Nsar AY, El-Maali EA, Abdel Hafez FF, Amin AF (2015) Prenatal Pesticide Exposure: Meconium as a Biomarker and Impact on Fetal Weight. J Environ Anal Toxicol 5: 268. doi:10.4172/2161-0525.1000268

Page 6 of 6

21. Kavvalakis MP, Tsatsakis AM (2012) The atlas of dialkylphosphates; assessment of cumulative human organophosphorus pesticides' exposure. Forensic Sci Int 218: 111-122.

22. Whyatt RM, Barr DB (2001) Measurement of organophosphate metabolites in postpartum meconium as a potential biomarker of prenatal exposure: a validation study. Environ Health Perspect 109: 417-420

23. Woodruff TJ, Zota AR, Schwartz JM (2011) Environmental chemicals in pregnant women in the United States: NHANES 2003-2004. Environ Health Perspect 119: 878-885.

24. Arcas MM, Lopez-Martinez C, Granada A, Olea N, Lorenzo-Tovar ML, et al (2010) Organochlorine pesticides in umbilical cord blood serum of women from southern spain and adherence to the mediterranean diet. Food and chem toxicol 48: 1311-1315.

25. Jonsson BA, Rylander L, Lindh C, Rignell-Hydbom A, Giwercman A, et al. (2005) Inter-population variations in concentrations, determinants of and correlations between 2,2',4,4',5,5'-hexachlorobiphenyl (cb-153) and 1,1-dichloro-2,2-bis (p-chlorophenyl)-ethylene (p,p'-dde): A cross-sectional study of 3161 men and women from inuit and european populations. Environ health. 4:27

26. Longnecker MP, Korrick SA, Moysich KB (2005) Human health effects of polychlorinated biphenyls. Dioxins and health: (edtn 2) John Wiley \& Sons 679-728.

27. Lopez-Espinosa MJ, Vizcaino E, Murcia M, Llop S, Espada M, et al. (2009) Association between thyroid hormone levels and 4,4'-DDE concentrations in pregnant women (Valencia, Spain). Environ Res 109: 479-485.

28. Govarts E, Nieuwenhuijsen M, Schoeters G, Ballester F, Bloemen K, et al (2012) Birth weight and prenatal exposure to polychlorinated biphenyls (PCBs) and dichlorodiphenyldichloroethylene (DDE): a meta-analysis within 12 European Birth Cohorts. Environ Health Perspect 120: 162-170.
29. Tsatsakis AM, Tzatzarakis MN, Koutroulakis D, Toutoudaki M, Sifakis S (2009) Dialkyl phosphates in meconium as a biomarker of prenatal exposure to organophosphate pesticides: A study on pregnant women of rural areas in crete, greece. Xenobiotica. 39: 364-373.

30. Whyatt RM, Barr DB, Camann DE, Kinney PL, Barr JR, et al. (2003) Contemporary-use pesticides in personal air samples during pregnancy and blood samples at delivery among urban minority mothers and newborns. Environ Health Perspect 111: 749-756.

31. Whyatt RM, Rauh V, Barr DB, Camann DE, Andrews HF, et al. (2004) Prenata insecticide exposures and birth weight and length among an urban minority cohort. Environ Health Perspect 112: 1125-1132.

32. Kezios KL, Liu X, Cirillo PM, Cohn BA, Kalantzi Ol, et al. (2013) Dichlorodiphenyltrichloroethane (DDT), DDT metabolites and pregnancy outcomes. Reprod Toxicol 35: 156-164.

33. Robins JC, Marsit CJ, Padbury JF, Sharma SS (2011) Endocrine disruptors environmental oxygen, epigenetics and pregnancy. Front Biosci (Elite Ed) 3 : 690-700.

34. Nieuwenhuijsen MJ, Dadvand P, Grellier J, Martinez D, Vrijheid M (2013) Environmental risk factors of pregnancy outcomes: A summary of recent metaanalyses of epidemiological studies. Environ Health 12:6.

35. Gomes J, Lloyd OL (2009) Oral exposure of mice to formulations of organophosphorous pesticides: Gestational and litter outcomes. Int J Environ Health Res 19:125-137.

36. Ahmed AE1, El-Mazar HM, Nagy AA, Abdel-Naim AB (2008) Chloroacetonitrile induces intrauterine growth restriction and musculoskeletal toxicity in fetal mouse. Toxicol Ind Health 24: 511-518.

37. Saillenfait AM, Gallissot F, Sabate JP (2009) Differential developmenta toxicities of di-n-hexyl phthalate and dicyclohexyl phthalate administered orally to rats. J Appl Toxicol 29:510-521. 